\title{
Transforming Introductory Psychology: Trading Ownership for Student Success
}

\author{
Randall E. Osborne \\ William F. Browne \\ Susan J. Shapiro \\ Walter F. Wagor \\ Indiana University East
}

As colleges struggle to maintain enrollments, many bave shiffed from a primary focus on recruitment of newo students to an increased focus on retaining students once they begin attending the college or university. An examination of introductory courses on our campus, however, revealed significant differences between faculty perceptions of student skills and the actual skills students brought into the classroom. This prompted shifts in the manner in which we teach introductory psychology on our campus in order to enhance the skills necessary for success in survey courses and to provide a foundation of learning and thinking skills that would translate to other courses. These changes bave resulted in enhanced consistency between sections of the course, increased cooperation between faculty teaching the course, and enbanced performance on the success measures we oullined for this project. This systematic transformation of the course and immediate and longterm outcome data are fully explored in this paper.

\section{INTRODUCTION}

Ollege campuses are clearly concerned with retention and gradua-
tion rates for students. Although on the surface retention may
appear to be a straightforward issue (either you retain students or you do
not), it is not that simple. There may be an intertwining set of factors 
present on many campuses that could interfere with student success. Although no single factor can account for all student losses or all student successes, when variables begin confounding each other, a negative cycle can start. It is possible, for example, that (1) typical factors that inhibit student retention, (2) faculty expectations for incoming students, and (3) traditional advising of students into introductory "survey" courses during their first year may interact with each other to have a negative impact on student success. In order to illustrate how these factors can influence each other, let us quickly examine each factor and its effect on student retention and success separately.

\section{Retention Predictors}

With the major emphasis placed on assessment by accrediting agencies (e.g., North Central) over the last ten years, campuses have become more aware of factors that mediate the success of students. Along with this increase in awareness has come the realization that retention is a major concern. Traditional thoughts about retention have also begun to change (American Association of State Colleges and Universities, 1997; Hyman, 1995). As campuses build retention programs that are more active and less reactive, retention and assessment efforts can be brought together. Different types of campuses, however, may deal with different retention issues (e.g., Allen, 1993; Borden, Burton, Evenbeck, \& Williams, 1997; McGivney, 1996; Pacheco, 1994; Seppanen, 1995). Residential campuses, for example, may face fewer retention concerns due to family conflicts than commuter campuses.

Commuter campuses struggle to maximize retention in the face of multiple factors that interfere with such efforts. Many of these factors were borne out on our own campus when we categorized entry data from students and made inquiries into the reasons students give for withdrawing from classes. Students cite a multitude of reasons for "dropping" or "stopping" out. These reasons include: (1) health, (2) finances, (3) changing work status, (4) childcare issues, (5) lack of preparedness, (6) lack of home support for study efforts, (7) poor time management, and (8) stress (Rickinson \& Rutherford, 1995). Clearly there is only so much that can be done to aid students with some of these issues. In our experience, however, too much emphasis is placed on those things campuses cannot change and not enough emphasis is placed on developing retention efforts around those factors that can be changed. 


\section{Faculty Expectations for Students}

Faculty may assume that students come to college with more skills than they do. A recent presentation at a national teaching conference (Sydow \& Sandel, 1996) illustrates this very point. According to the authors, college instructors' expectations for students do not closely parallel student abilities coming into the classroom or students' expectations for what the college experience will be like.

A recent survey of faculty on our own campus confirms this misperception. Instructors teaching introductory courses (including a "first year experience" course) were asked to list the assumptions they made about students entering their classes. A majority of the faculty endorsed a consistent set of attributes or expectations for students entering the college classroom. These expectations and abilities include (1) critical thinking, (2) time management, (3) goal-setting skills, (4) the ability to apply course concepts to the "real" world, (5) active reading, (6) learning-style flexibility, and (7) intrinsic motivation to succeed. When faculty were asked to cite reasons why students do not succeed in college, the most common responses were (1) lack of effort, (2) poor time management, (3) lack of maturity, and (4) not enough time to complete all demands in their lives. Although a significant number of faculty also mentioned "underpreparedness" as a contributing factor, few offered any suggestions as to what was meant by that word.

Do entering students have the skills college faculty expect? It probably comes as no surprise that entering students are deficient in the very areas in which faculty expect them to have attained some degree of competency. All entering students on our campus must complete entry assessments, which are used to assess reading level and mathematical ability and to place students into the correct level of English composition. Herein lies the dilemma. Whereas most faculty expect students to be prepared for college-level work, $70 \%$ of our entering students place into one or more of our developmental courses. These developmental courses are considered "pre-college." This discrepancy between faculty expectations and student abilities creates the potential to exacerbate any retention problems a campus may have.

\section{Tendency to Place Incoming Students into Survey Courses}

Survey courses such as introductory psychology are often quite difficult for students. Courses that sample many topics in modest depth and then move on, as is typical in an introductory-level psychology course, are quite difficult for students with less than solid academic skills. Research 
also suggests that the gap between student preparedness and faculty expectations in survey courses is exacerbated in courses in which little written work is required (Boice, 1990; Rickabaugh, 1993). All of these difficulties are particularly relevant for students on our campus, many of whom are not coming directly from high school but are returning to college after an extended break in their education.

In addition to issues of academic preparation, Snowman (1996) suggests that first-year students cannot succeed without more finely developed study skills. Certainly faculty and teaching assistants can facilitate study skills development in students. But the research clearly shows that study skills are irrelevant if students do not develop metacognitive abilities (Flavell, 1979; Gardner \& Boix-Mansilla, 1994). As mentioned previously, however, entrance test scores on our campus place $70 \%$ of students into one or more developmental courses (e.g., algebra, composition, reading). Given that most students need 12.15 credit hours per semester to qualify for financial aid, a typical semester for a first-semester student on our campus may include developmental math, developmental composition, college textbook reading, and a survey course like introductory psychology. As outlined already, these survey courses require many (if not all) of the skills these students do not have. At the very time they are taking the developmental courses to enhance the skills necessary to succeed in college, they are being placed in survey courses in which faculty expect those skills to already be in place.

We could be setting many students up for failure. Introductory psychology is a historically difficult course for most students. Data from our university system show most campuses report " $D$, , " $F$," and withdrawal rates from introductory psychology courses as high as $45 \%$. However, it is highly unlikely that students will stop taking introductory survey courses during their first academic year. Therefore the burden for enhancing success rates in such courses lies with the faculty teaching these courses. Seven years ago our department implemented a project to assist in the success and retention of students designated by entrance variables as "at risk." Although many of the above mentioned variables that negatively affect retention seem beyond our control, we believed there were many upon which we could have a positive impact.

Recent campus discussions with area high school counselors suggest critical thinking, a common theme in college courses, may not be emphasized in high school courses. It was our belief that focusing on and fostering entry-level students' critical thinking skills would enhance their ability to succeed in their first semester. We also thought that these 
increased thinking skills would translate into greater self-confidence thereby motivating retention across semesters.

\section{The Transformation}

Over the past seven years, we have made systematic revisions to our general psychology course that we believe have had a significant positive impact on student success and retention. Over the next several pages, we will outline the steps in this transformation: (1) developing a core set of learning objectives that all faculty would use when teaching the course; (2) training and employing undergraduate students as teaching assistants in the general psychology course; (3) implementing a two-credit-hour critical thinking lab that was a co-requisite with limited sections of the general psychology course; (4) deciding that all sections would be taught by three faculty, each with primary responsibility for one-third of the course material; and (5) fully integrating the course so that the threefaculty team teaches the course. This team-taught format includes team writing all assignments and exams.

\section{Developing Departmental Objectives for Introductory Psychology}

We worked as a department to develop a set of learning objectives for all students taking the introductory course. Regardless of instructor, then, the expectation was that students would learn the information listed in the objectives. We approached this task by asking ourselves, "If this is the only psychology course that a student will ever take, what do we feel this student must know about psychology?"

Given our belief that the objectives represented the most important material that students leaving the introductory psychology course should know, we decided to design and implement a departmental comprehensive final exam as well. Students in all sections of the introductory psychology course from that point on (seven years now) were given a teamwritten, comprehensive final exam based on those team-developed, departmental course objectives. A sample of the chapter learning objectives for this course is included in Appendix 1.

These objectives are given to all faculty who teach the course and also to students along with the syllabus for the course. Students are encouraged to use these objectives as they study for course exams and to understand what information they should be garnering from the textbook. If, for example, during the social psychology section of the course a learning objective is listed that is not discussed in class, the students are 
encouraged to pay particular attention to that part of the social psychology chapter and to be able to answer questions about that concept at the level at which the objective is written.

As the reader will note by reading the sample objectives listed in Appendix 1, the level of the objectives vary. If the objective states that students should be able to "apply the concepts of inhibition, excitation, and threshold to examples of neural activity, "for example, then exam questions are written at this "application" level. If an objective states that students will "know the meaning of ___, then a comprehensionlevel question will be written based on that objective.

Each faculty member started the process of writing course learning objectives by writing objectives in his or her specialty area. These lists were then distributed to the other faculty and discussed at a departmental meeting. If other faculty had questions about the inclusion of certain objectives or the exclusion of others, the faculty member who developed the objectives for that chapter would explain his or her rationale. If there was disagreement about the inclusion of a certain objective, we attempted to reach a compromise. If such a compromise was not reached, a vote on that objective would be taken. This process continued until we had a defined set of objectives that all faculty would use.

\section{The Use of Undergraduate Teaching Assistants}

Undergraduates receive training as Teaching Assistants (TAs) by taking a course on "Psychology Applied to Teaching." This course covers basic teaching skills as well as reflective teaching, managing group work, motivating students, meeting different student needs, understanding learning styles, classroom management, developing goals and objectives, planning for attaining goals and objectives, test construction and administration, and grading student achievement.

As a final component for the course, students are required to write a reflective statement of teaching philosophy. To help students begin developing their teaching statements, we give them examples of departmental faculty members' teaching philosophies and ask them to discuss how each faculty member's approach to teaching reflects his or her philosophy. We feel that this exercise is particularly important. The course is designed to help future TAs understand the proactive nature of the educational environment. Faculty do spend a lot of time reacting to student emergencies, changing schedules, weather delays, and other unforeseen obstacles. But the majority of what occurs in the classroom needs to be developed with forethought. By having students examine others' 
statements and create their own, we are able to use the teaching philosophy as a basis for reflective thinking about teaching and the choices one makes about what to do or not do in the classroom.

\section{The Critical Thinking Lab}

With a newly trained cadre of TAs, we were ready to move to the next phase in the development of the general psychology course. If students were going to learn new and more effective methods for thinking, those skills would need to be practiced on a very regular basis. For this reason, we developed a two-credit-hour critical thinking lab. This lab was paired as a co-requisite with some sections of our general psychology course. Prior to the implementation of this two-credit-hour critical thinking lab, $46 \%$ of the students were receiving either " $D$ " or " $F$ " grades or were withdrawing prior to the end of the semester. In developing this lab, we incorporated two major themes that we felt would assist students in being more successful as learners: cognitive levels and critical thinking. Although there are many educational viewpoints on cognitive levels and many critical thinking paradigms available, we chose to adopt Benjamin Bloom's (1956) taxonomy of cognitive objectives and Randolph Smith's (1995) seven characteristics of a critical thinker.

We adopted Bloom's (1956) cognitive levels to assist students in reflecting on their own thinking. Bloom suggests that many students are unpracticed in going beyond the knowledge level of information. This matched our own thinking about the challenges faced by students in many survey courses. If those courses simply ask students to recall facts, most students can do so competently. If, however, such courses expect students to apply those facts and use them in novel ways, most students will be unprepared to do so. We also felt, however, that such skills can be taught. The two-hour lab course provides us with the appropriate environment for teaching such skills and allows students to practice them multiple times and in multiple ways.

For example, we expect students to go beyond mere memorization or recitation of facts and expect them to assess their comprehension and analyze interconnections among ideas. An important aspect of the analysis process is the ability to break information down into subparts and retain and utilize only those subparts that are meaningful. Any extraneous information should be discarded. Teaching students how to break information down into meaningful units aids them in assessing what information is most important to retain and what can be discarded or, at least, ignored. 
Our desire to emphasize student's thinking skills led us to search for a useful definition of critical thinking. For our approach to critical thinking, we adapted Smith's (1995) definition of the seven characteristics of a critical thinker. According to Smith, critical thinkers (1) are flexiblethey can tolerate ambiguity and uncertainty, (2) identify inherent biases and assumptions in their thinking, (3) maintain an air of skepticism and ask, "What am I being asked to believe?", (4) are able to separate opinions from facts, (5) do not oversimplify or, in our opinion, make things overly complicated, (6) use logical processes to make inferences and connections, and (7) examine all available evidence before drawing conclusions. We felt that, regardless of degree program, student success would be enhanced if they could develop these seven characteristics.

It is important for the reader to note that we do not believe critical thinking can be taught as "content." Instead, it is taught as a process. It is a goal that is approached with systematic and continuous practice. We felt it was important to put critical thinking within a context. For this reason, we paired the critical thinking lab with the introductory psychology course. This pairing allowed us the additional benefit of being able to explore the degree to which fostering such abilities might impact success in our introductory course.

We developed critical thinking assignment sheets and group activities that encouraged students to expand their thinking in relation to content issues from the introductory psychology course. These assignments encouraged students to think in non-traditional ways. Group work was the primary mode of instruction, with faculty and teaching assistants "working" the room to encourage debate and keep the groups on task. Many of the activities were taken directly from Smith's book. One such activity, for example, asks students to imagine that they are on Clinton's re-election team. Their task is to devise a survey that would yield results favorable to Clinton's re-election. After completing this part of the assignment, the same groups are required to develop a survey that would lead to results unfavorable to Clinton's re-election. Such an assignment reinforces many of the concepts covered in the research methods section of the introductory course but places that information within the context of critical thinking.

To help make this formalized method of thinking more automatic, we decided to engage students in frequent and systematic analyses of their own thinking and designed a scoring rubric that reflected the comprehensive thinking we were striving to model. During one class period, for example, students watch a television news magazine show and are 
asked to use Smith's characteristics of critical thinking to analyze the program. Did the presenter, for example, analyze the information and discard meaningless information? Once students use the scoring rubric to analyze the program, they are put into groups to discuss their analysis. We use this scoring rubric as the primary method of evaluation to encourage students to reflect continuously on their thinking and the thinking of others. Whenever students turn in an assignment, we use this rubric and return the completed form with the student work. A copy of this rubric is included in Appendix 2.

We also encourage self-reflection by requiring students to turn in a daily "exit card" at the end of the class period. On these cards, we ask students to describe which critical thinking characteristic the activities from the lab reinforced, what cognitive level we had attained that day, and a rationale for their answers. In addition, any assessment comments are welcomed from students. The course faculty member and the TAs read these cards and then write personal responses on each, returning the cards the next class period.

\section{A Sample In-Class Activity}

One particular activity was listed by $88 \%$ of the students as the most influential in illustrating how challenging critical thinking can be. Four cards were placed on a sheet of paper and then copied onto an overhead transparency. The cards (from left to right) were (1) the king of hearts, (2) the three of clubs, (3) the jack of hearts, and (4) the five of clubs. Students were placed into groups and asked to look over the sequence of cards and to generate a hypothesis that would predict what the next several cards would be. Once students decided on what they believed the sequence to be, they were instructed to test the hypothesis by telling either the instructor or one of the teaching assistants what they believed the next card would be. In return, they would receive a "yes" or "no" response. A "yes" response, of course, would simply indicate that the card they chose fit the sequence.

On the surface this may seem easy, but it proved extraordinarily difficult for students. Most groups immediately predicted that the fifth card would be the nine of hearts (based on the hypothesis that the sequence was descending and skipping heart cards). Shocked expressions greeted the faculty member and TAs when they told students that this answer was incorrect.

This process continued for over 20 minutes and groups were gently nudged and prodded to try different hypothesis testing approaches. The 
activity clearly illustrated for students that they needed to be more flexible in their thinking. When students were told that a good scientist would approach this task by trying to pick cards that might prove her hypothesis wrong rather than trying to prove herself right, performance started to improve.

The typical approach of believing that it was the suit of the card that mattered could result in many "false positive" responses. Students might believe they had accurately determined part of the sequence because they had guessed the fifth, sixth, and seventh cards only to be told "no" when they guessed the eighth card. By trying to prove themselves right, or changing too many variables at once (like changing from a face card to a numbered card as well as changing the suit in the same guess) students had to start over when they received a "no" response.

Once students tried to prove themselves wrong by inserting other suits, they made quick progress. Ultimately, all groups completed the task having discovered the hypothesis statement that the instructor and teaching assistants had decided upon prior to the activity. The sequence that would always receive "yes" responses was "a face card followed by a numbered club."

The themes of challenging what is known, exploring one's hypotheses, and trying to prove oneself wrong are carried throughout all activities in the course. Students are taught to "invest" in their critical thinking and to understand how to reap the benefits of making that investment. Critical thinking requires more time and effort and may force one to reveal biases and assumptions inherent in one's thinking. But, in return for such an investment, students learn they gain more pure knowledge and can be more certain of what they know and why they know it. These skills, we believe, aid students as they take other courses within their degree programs.

\section{Results of the First Transformation of the Course}

A recent analysis of our data supports our notion that emulating Smith's seven characteristics of critical thinking enhances student success. Students completing the critical thinking course along with the general psychology course outperformed the matched sample on all variables regardless of academic major.

Ninety-two students completed the critical thinking lab with a paired general psychology course across those five semesters. In order to assess the impact of the critical thinking lab we created a matched sample cohort. The matched sample, drawn from regular sections of the general 
psychology course during the same semesters, was created based on entering scores on the campus entry assessments, high school rank, gender, ethnicity, declared major (if applicable), and semester in college.

Recall that prior to this project the average " $\mathrm{D}$," "F," and withdrawal rate in our introductory course was $46 \%$. The average " $D$," " $F$," and withdrawal percentage across the five semesters in which the critical thinking lab was attached to the introductory course was $24 \%$.

In addition, the graduation rate of students who completed this version of the introductory psychology course (recall that these students were also designated by the university as the most "at risk" for academic failure) was $14 \%$ higher than for the matched cohort of students who took the traditional introductory course during the same semesters. Lastly, upon graduation, students who had completed the combined introductory psychology/critical thinking course had an overall GPA that was over one letter grade higher than the matched cohort sample.

\section{The Second Transformation of the Course}

Once we realized that the critical thinking laboratory could have such a powerful impact on student success and retention across semesters, we felt obliged to implement changes that would bring those advantages to all students who enrolled in the introductory course. To accomplish this, we knew we had to develop a method for ensuring consistency of coverage and expectations across the sections of the introductory course. Since we had recently developed an entire set of learning objectives for this course, a set that all faculty teaching the course would be held accountable to, it seemed the right time to expand the critical thinking experiences into all sections of introductory psychology.

At this point, the need for our own professional development as teachers became quite obvious and relevant to us. Many faculty felt they should have full control of the classroom and the content. Academic freedom was mentioned many times when faculty felt they were being "told" what to do or not do in the classroom. But we had data in hand suggesting very strongly that changes we had made on an experimental basis in some sections of our introductory psychology course were having profound positive effects on students. We could not ignore the obligation that came with such a discovery.

With the newest phase in the transformation of the course, the faculty moved to larger sections (up to 90 students when the previous enrollment cap had been placed at 50) with the continued aid of our undergraduate teaching assistants. These larger groups of students, how- 
ever, were also required to enroll in a one-hour, content-based activity lab. Our campus policy requires $21 / 2$ hours of contact per week for a three credit hour course. We reduced our "lecture" class time to two hours and converted the additional half hour of lecture time into one hour of "lab time." The faculty designed "content" laboratories that supported course content covered during the preceding week.

In addition three faculty now team-teach the course, with each faculty member taking primary responsibility for teaching one-third of the course and designing the lab activities that support her/his content weeks. We offer two sections of the course each semester. One section meets twice a week for one hour each day. The second section is a night section that meets once each week for two hours. During each section of the course, the faculty persons not having primary teaching responsibility alternate attending the day and the night sections. The undergraduate teaching assistants also attend one of the course sections in addition to conducting at least one of the weekly activity labs.

We begin the lab sessions with sessions on study skills and critical thinking. Beginning in the third week, labs involve hands-on experience with course material covered the previous week. The week following the presentation of social psychology, for example, students are taught how to recognize persuasion cues and analyze television commercials. The week following the presentation on memory, interactive activities on memory (such as demonstrating primacy and recency effects) are presented. In addition, we now teach all sections of the introductory psychology course in our full-technology classrooms. All class sessions and presentations fully incorporate our available technology, and all lectures are now presented via PowerPoint. We are beginning to incorporate QuickTime video presentations and additional graphics within the PowerPoint presentations as well.

\section{The Results from the Latest Transformation}

We have implemented this team-taught procedure for two semesters and are now ready to report on the preliminary results. During the fourth week of classes we are required to send "early warning" reports to students who are in danger of performing poorly in the course due to poor attendance, poor exam grades, incomplete work, etc. During the early warning this past semester (the second semester of the "team taught lab activity" project), the average attendance percentage in the introductory course was up by $22 \%$. In addition, the average withdrawal rate was down by $19 \%$. Three semesters ago (prior to implementing the new, revamped 
introductory course with undergraduate teaching assistants leading lab sessions) the average grade of students in the introductory psychology course was $71 \%$. After implementation of the required lab and the new team-taught format, the average course grade for the day sections (with a majority of "traditional" aged students) was $78 \%$, and the average course grade for the night section (with more "non-traditional" aged students) was $80 \%$. During the second semester, the average day section mid-term grade was $83 \%$, and the average mid-term grade for the night section was $82 \%$.

\section{Conclusion}

By placing our own control over content aside and working as a team, we have developed an approach to teaching the introductory psychology course that appears to be having positive short-term (higher course grades, better attendance, fewer " $D$, , " $F$," and withdrawal grades) and long-term (overall higher GPA upon graduation, increased graduation rate) effects on students. Student course performance is an entire letter grade higher even though we are utilizing the same battery of test questions, the same departmental final exam, and the same categories of assignments we have used in previous years. By engaging in research on the impact of the critical thinking lab course and the team-taught version of the general psychology course, we have discovered information that has caused us to reexamine how our introductory courses are taught.

We feel that we have also gained better insight into the teaching/ learning process. Students comment about enjoying the variety of lecture and activities. The faculty work closely to write exams, to solve problems, make decisions about student emergencies, and continuously monitor the process. Although it is difficult to "give up" some of our favorite things to teach in the class, we feel obligated to do so to the extent that such material is not a part of the agreed-upon objectives.

As we continue to move forward with our assessment model, we intend to find newer and ever more creative ways to enhance our own professional development as educators by trading ownership for student success. Much of our "affective" data comes from the students themselves. Students complete written work during every class period and are asked to complete assessment instruments many times throughout the semester as well. Overall, the response to the new format is quite positive. Eightyseven percent $(\mathrm{N}=104)$ of students rate themselves as "agreeing" or "strongly agreeing" with the statement, "The activities helped me with the 
content, and I can use what I have learned." In addition $88 \%$ "agree" or "strongly agree" with the statement, "The teaching methods used helped me gain important information and understanding of the unit topic."

In addition to enhancing students' feelings about the general psychology course, anecdotal feedback from students and the teaching assistants about the team-taught approach is quite positive. Other faculty in other disciplines are asking us about the new format, and some have mentioned that students enrolled in the course have responded favorably to them about the approach. Teaching assistants state that numerous students have talked about the excitement and collegiality in the department.

We include brief written reflection in every class period and end each unit of material by asking students to share the strengths and areas in need of improvement from that unit. These end-of-unit assessment cards have provided a wealth of information for our continual improvement of the course and our team-teaching approach. Under strengths some representative comments include:

- "I like having three instructors teaching-it keeps things interesting."

- "Each instructor is different, but it is obvious each of you knows your stuff."

- "I like the use of in-class activities and many, many examples."

- "I can see how this information is going to help me as a future nurse."

- "I didn't realize psychology included so much. This really opened my eyes."

Comments about areas in need of improvement have been very helpful as we attempt to fully integrate the team-taught format. During the first semester of team-teaching, we utilized a form of "tag-team-teaching." Each of us was responsible for one-third of the material and we organized that material into units. During "our" unit, each of us took primary responsibility for teaching the material, scoring assignments, and writing the exam.

Multiple student comments identified a particular exam by using the instructor's name such as, "the question about Social Comparison on Osborne's exam. .." This kind of comment suggested to us that students did not truly perceive our course as a team effort. We now attend all class sessions together, use scoring rubrics for all assignments, divide up the grading, and write the exams collaboratively. Student assessment 
comments suggest this collaborative approach embodies the type of team work we want students to recognize.

- "I really like having three instructors to teach me. I can ask any one of you for help."

- “Three teachers for the price of one-what a deal!"

- "It is very informative when the three of you teach together."

- "It is interesting how your perspectives differ yet it helps me learn."

As we peruse assessment comments, several themes emerge. The most important for us centers on students' positive reactions to the benefit of having three teachers. As we discuss course concepts, all three faculty will offer suggestions, ways to approach the concept, and advice for how best to learn the nuances of each concept. This is reflected in student comments such as, "When the three of you describe something there is bound to be one description that really works well for me."

A second theme centers on excitement. We want the students to be excited about the discipline and we wish to model that excitement. General psychology courses are recruiting grounds for new majors. If we can share some of our excitement with students, not only will they learn the course material better, they may be motivated to apply that material beyond this one, simple course and may sample additional coursework. Comments such as, "It is pretty obvious that the three of you are excited about what you do," provide evidence to us that students are, indeed, perceiving this excitement.

By developing ourselves professionally and trading traditional academic "ownership" for a more consistent and well-designed set of courses, we are ensuring more success for the students who take our courses. In addition, we are mentoring and role-modeling for the next generation of professionals who will teach in our discipline by taking our undergraduate TAs to teaching and research conferences and helping them as they present their ideas for professional critique.

We are now turning our attention to our lifespan development course. This is another multiple section course. We have already developed a set of departmental themes for the course and are considering a team-taught, integrated approach to teaching it as well. We have developed a cadre of assignments that appear to better meet the needs of our students. Although psychologists write the textbooks for such a course, and the course is taught by those of us in the psychology department, the majority of students who take the course are education, nursing, and 
social work majors. The assignments we have designed allow students to apply course concepts to solving problems they might encounter in their chosen profession. Student evaluations of these assignments are quite positive and advisors from the aforementioned disciplines have commented favorably on the preparedness of students completing the lifespan development course.

\section{Final Thoughts}

Transforming a course from multiple sections with no explicit consistency to one that is team-taught is difficult at best. Faculty perceptions of "owning" the classroom come into direct conflict with the desire to ensure consistency between sections of the introductory course. As we have experienced this transformation over the past seven years, we have identified several issues that could either interfere with such efforts or enhance the potential for success of these efforts. We leave you with these things we have learned.

- Make a careful decision about what method to use for developing the list of course learning objectives. We began by letting faculty develop learning objectives for those sections of the course about which they cared the most. Only after allowing faculty to defend their choices did we make attempts at compromise. Looking back, this may have resulted in unnecessarily long lists of objectives that we trim annually. Another tactic might be to have faculty develop the learning objective lists for chapters that are outside their areas of expertise. Thus, if someone else wants a certain concept to be included, he or she would have to argue convincingly for its inclusion.

- Such efforts need to be rewarded. Reference to these efforts should be made in annual service reports, and recognition of the difficulty of team-teaching such sections should be made when calculating faculty teaching loads.

- Continuous assessment is absolutely essential with constant vigilance over what the desired outcomes might be. If student learning is the desired outcome, then constant assessment data should be gathered and analyzed to determine if student learning is increasing.

- If the department is large, only those interested in the introductory course should be required to be a part of the process. As long as departmental faculty are willing to have the proposed product brought forward for a vote upon completion, the primary work is best handled by those most concerned with the introductory course. 
- Efforts must be taken to allow faculty to utilize their preferred methods for achieving course goals. Lectures need not be used, for example, if the faculty member is more comfortable with first exposure methods (e.g., reading the chapter before it is discussed, completing a chapter quiz, and then discussing it during class).

- The focus must be kept on the outcome goals and not the process each faculty member uses to move students toward those outcomes.

- A firm commitment must be made by a departmental dean or chair to invest in the transition. In other words, the risk involved must be formally recognized and a commitment must be made to see the course through several transformations before decisions are made about the success of the new method. Such change will not bring about desired outcomes overnight. The department must invest in a long-term process of change.

- The faculty working to revise the course cannot work in isolation. By knowing what the other faculty will teach, they can design a more integrated course. Having faculty attend all sections of the course and holding weekly meetings can significantly increase the cohesiveness of the course.

- If a "team-taught" persona is desirable, it is best not to have a single faculty member teach large portions of the course. It is better to have faculty rotate weekly to reinforce for the students that the effort is an integrated one.

- It is imperative for faculty to prepare for the impact team-taught sections will have. We have gone from maximum enrollments of 50 per section (when taught individually) to sections of 90 . Although this may seem minimal given that three faculty team-teach the course, it makes learning students' names much more difficult and also limits the amount of interactive work that can be done during the regular class sessions (as opposed to the activity labs).

\section{REFERENCES}

Allen, B. A. (1993). The student in higher education: Nontraditional student retention. Community Services Catalyst, 23, 19-22.

American Association of State Colleges and Universities. (1997). Policies and practice: $A$ focus on bigher education retention. Washington, DC. 
Bloom, B. S., Englehart, M. B., Furst, E. J., Hill, W. H., \& Kratwohl, O. R. (1956). Taxonomy of educational objectives: The classification of educational goals. Handbook 1: The cognitive domain. New York, NY: Longman.

Boice, R. (1990). Faculty resistance to writing-intensive courses. Teaching of Psychology, 17, 13-17.

Borden, V. M. H., Burton, K. L., Evenbeck, S. E., \& Williams, G. A. (1997). The impact of academic support programs on student performance and persistence. Research Brief, 4, 1-16.

Flavell, J. H. (1979). Metacognition and cognitive monitoring: A new area of cognitive developmental inquiry. American Psychologist, 34 (10), 906-911.

Gardner, H., \& Boix-Mansilla, Z. (1994). Teaching for understanding-within and across disciplines. Educational Leadership, 51 (5), 14-18.

Hyman, R. E. (1995). Creating campus partnerships for student success. College and University, 7, 2-8.

McGivney, V. (1996). Staying or leaving the course: Non-completion and retention. Adults Learning, 7, 133-135.

Pacheco, A. (1994). Bridging the gap in retention. Metropolitan Universities: An International Forum, 5, 54-60.

Rickabaugh, C. A. (1993). The psychology portfolio: Promoting writing and critical thinking about psychology, Teaching of Psychology, 20, 170-172.

Rickinson, B., \& Rutherford, D. (1995). Increasing undergraduate student retention rates. British Joumal of Guidance and Counseling, 23, 161-172.

Seppanen, L. (1995). Implicalions for retention strategies of differential student progress rates and the literature on student retention. (Research Report No. 95-4). Olympia, WA: Washington State Board for Community and Technical Colleges, Education Division.

Smith, R. A. (1995). Challenging your preconceptions: Thinking critically about psychology. Pacific Grove, CA: Brooks/Cole Publishing.

Snowman, J. (1996). Research in action: Becoming a better teacher. Midwestern Educational Researcher, 9 (2), 28-31.

Sydow, D. L., \& Sandel, R. H. (1996, May). Making student retention an institutional priority. Paper presented at the National Institute for Staff and Organizational Development Conference on Teaching and Leadership Excellence. Austin, TX. 


\section{Contact:}

Randall E. Osborne

Indiana University East

Middlefork Hall \#352

2325 Chester Boulevard

Richmond, IN 47374

(765) $973-8445$

(765) 973-8508 (FAX)

reosborn@Indiana.edu

Randall E. Osborne is Associate Professor of Psychology at Indiana University East. His teaching interests include Social and Abnormal Psychology and specialty courses on self-concept and self-esteem development and Psychology in the Courtroom. Dr. Osborne's research interests focus on self-concept, selfesteem, and factors that influence student success such as the relationship between pedagogy and student learning.

William F. Browne is Professor of Psychology at Indiana University East and Chair of the Behavioral and Social Science Division. His primary teaching focus is on training future college teachers, specifically undergraduate teaching assistants. Dr. Browne's research interests center on child and adolescent development and a cross-cultural analysis of adolescent self-concept and attitudes toward life.

Susan J. Shapiro is Associate Professor of Psychology at Indiana University East. Her primary teaching responsibilities include sensation and perception, behavioral neuroscience, and an online general psychology course. Dr. Shapiro's scholarly interests include applying the discipline of psychology to improve classroom interactions, student learning, and interactions with technology.

Walter F. Wagor is Associate Professor of Psychology at Indiana University East and currently serves as Assistant Vice Chancellor for Assessment. In addition to General Psychology, he regularly teaches Life Span Development, Learning, and Cognitive Psychology. Dr. Wagor's scholarly interests include student learning, assessment, teaching improvement, and youth violence. 


\section{APPENDIX 8.1}

\section{SAMPLE OF DEPARTMENTAL OBJECTIVES FOR INTRODUCTORY PSYCHOLOGY}

I. Introduction

A. Definition and History

Formulate an accurate definition of the science of psychology.

1. Identify its goals.

2. Outline and discuss the development of Psychology as a science.

B. Contemporary Perspectives

1. Compare and contrast the major assumptions and methods of the five contemporary perspectives: psychoanalytic, behavioral, humanistic, biological, and cognitive.

2. Recall or recognize important names associated with the various perspectives.

C. Research Methods

1. Classify variables in examples as independent and dependent.

2. Differentiate between experimental and control variables.

3. Justify the use of random subject assignment.

4. Compare and contrast experimental and non-experimental research techniques.

5. Describe and explain bias and placebo effects in psychological research.

6. Classify research as ethical or unethical in accordance with the principles of the American Psychological Association.

D. Statistics

1. Identify and define mean, median, and mode.

2. Define variability and explain how the Standard Deviation and Range are used to measure it.

3. Describe the normal curve and discuss its use in psychology.

4. Explain the concept of statistical significance as it is used in evaluating research hypotheses.

5. Interpret correlation coefficients.

E. Interpret information when presented in tables, diagrams, and graphs.

II. Biological

A. Describe the neuron

1. Describe the basic structure of the neuron and the relationship of this structure to its function

2. Comprehend the process of neural communication and demonstrate this by being able to: 
a. Describe the structure and function of the synapse.

b. Describe the function of neurotransmitters and give an example.

c. Apply the concepts of inhibition, excitation, and threshold to examples of neural activity.

B. Peripheral nervous system

1. Discriminate between the structures and functions of the sympathetic and parasympathetic nervous systems.

2. Define homeostasis and give examples of mechanisms which promote it.

C. Central Nervous System

1. Name and locate the basic structures in the central nervous system on a diagram or model.

2. Describe the function of named structures.

3. Apply knowledge of function in the central nervous system to understanding the effects of brain injury by describing the effects of injury to a particular structure in the brain.

4. Structures to be identified and described include:

a. Corpus callosum

b. Localization of function

c. Somatosensory

d. Motor cortex

e. Primary Visual

f. Primary Auditory

g. Thalamus

h. Hypothalamus

i. Limbic System

D. Endocrine

1. Name the structures which make up the endocrine system.

2. Describe the function of the structures which make up the endocrine system.

E. Genetics

1. Discuss the interaction between Nature and Nurture. 


\section{APPENDIX 8.2}

Project/Assignment/Activity Grading Sheet for B252-Critical Thinking

Content $=$

(Average Scale Point Circled Equals Points Earned)

Scale Used:

\begin{tabular}{|c|c|c|c|c|c|c|}
\hline \multicolumn{7}{|c|}{ 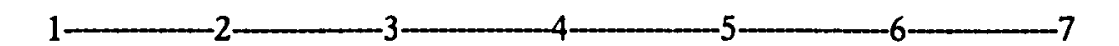 } \\
\hline $\begin{array}{l}\text { Major } \\
\text { Problems } \\
\text { in Most } \\
\text { Areas }\end{array}$ & $\begin{array}{l}\text { Major } \\
\text { Problems } \\
\text { in Many } \\
\text { Areas }\end{array}$ & $\begin{array}{l}\text { Major } \\
\text { Problems } \\
\text { in Some } \\
\text { Areas }\end{array}$ & $\begin{array}{l}\text { Minor } \\
\text { Problems } \\
\text { in Most } \\
\text { Areas }\end{array}$ & $\begin{array}{l}\text { Minor } \\
\text { Problems } \\
\text { in Some } \\
\text { Areas }\end{array}$ & $\begin{array}{l}\text { Few } \\
\text { Problems }\end{array}$ & $\begin{array}{l}\text { Little or } \\
\text { No } \\
\text { Problems }\end{array}$ \\
\hline
\end{tabular}

1.) The material presented was understandable.

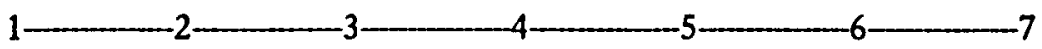

2.) The content covered was covered accurately.

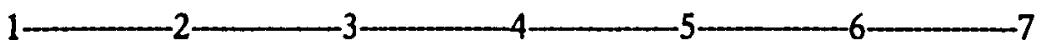

3.) The assignment was well organized.

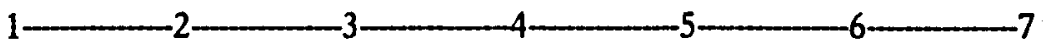

4.) Student work met defined criteria.

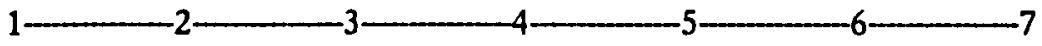

5.) The material being presented was understandable.

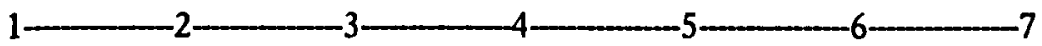

Critical Thinking Characteristics $=$ (Average Scale Point Circled Equals Points Earned)

\begin{tabular}{|c|c|c|c|c|c|c|}
\hline \multicolumn{3}{|c|}{2} & \multicolumn{2}{|l|}{-4} & $\ldots$ & -7 \\
\hline $\begin{array}{l}\text { Major } \\
\text { Problems } \\
\text { in Most } \\
\text { Areas }\end{array}$ & $\begin{array}{l}\text { Major } \\
\text { Problems } \\
\text { in Many } \\
\text { Areas }\end{array}$ & $\begin{array}{l}\text { Major } \\
\text { Problems } \\
\text { in Some } \\
\text { Areas }\end{array}$ & $\begin{array}{l}\text { Minor } \\
\text { Problems } \\
\text { in Most } \\
\text { Areas }\end{array}$ & $\begin{array}{l}\text { Minor } \\
\text { Problems } \\
\text { in Some } \\
\text { Areas }\end{array}$ & $\begin{array}{l}\text { Few } \\
\text { Problems }\end{array}$ & $\begin{array}{l}\text { Little or } \\
\text { No } \\
\text { Problems }\end{array}$ \\
\hline
\end{tabular}

1.) Project showed flexible thinking.

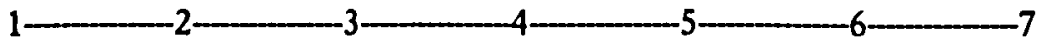

2.) Project identified inherent biases and assumptions.

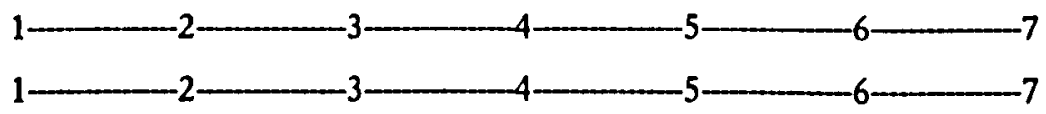




$\begin{array}{lllllll}\text { Major } & \text { Major } & \text { Major } & \text { Minor } & \text { Minor } & \text { Few } & \text { Little or } \\ \text { Problems } & \text { Problems } & \begin{array}{l}\text { Problems } \\ \text { in Most }\end{array} & \begin{array}{l}\text { Problems } \\ \text { in Many }\end{array} & \begin{array}{l}\text { in Some } \\ \text { in Moblems }\end{array} & \begin{array}{l}\text { Problems } \\ \text { in Some }\end{array} & \begin{array}{l}\text { No } \\ \text { Problems }\end{array} \\ \text { Areas } & \text { Areas } & \text { Areas } & \text { Areas } & \text { Areas } & & \text { Problem }\end{array}$

3.) Project maintained skepticism with accepting statements from others.

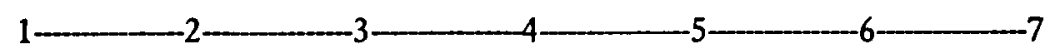

4.) Project separated opinion from fact.

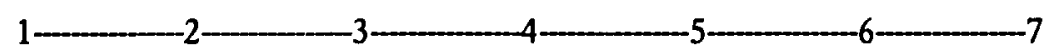

5.) Project did not oversimplify.

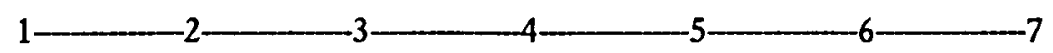

6.) Project utilized logical inferences.

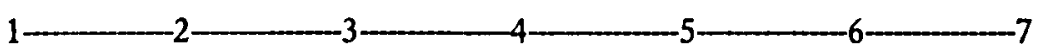

7.) Project examined available evidence before drawing conclusions.

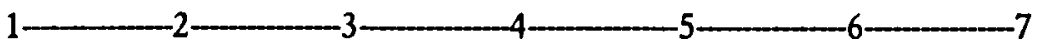

Bloom's Cognitive Objectives $=$

(1 point for each "yes" checked)

1.) Appropriate mount of knowledge demonstrated.

2.) Knowledge was correctly used to demonstrate comprehension. no

- yes _ no

3.) Information was applied to real world problems. _- yes _ no

4.) Information was analyzed into meaningful units. __ yes _ no

5.) Information synthesized into new knowledge. _ _yes _ no

6.) Student evaluated learning to test for accuracy. _ yes _ no

Total Grade $=$ Content + Critical Thinking + Bloom 